\title{
Cognitive performance in patients with chronic tension-type headache and its relation to neuroendocrine hormones
}

\author{
Mamdouh Ali Kotb ${ }^{1,2^{*}} \mathbb{D}$, Ahmed M. Kamal ${ }^{3,4}$, Daifallah Al-Malki ${ }^{1}$, Aliaa S. Abd El Fatah ${ }^{5}$ and Yassmin M. Ahmed ${ }^{6}$
}

\begin{abstract}
Background: Tension-type headache is the most common headache to be seen in clinical practice. Depression is highly prevalent in chronic tension-type headache $(\mathrm{CTTH})$ patients attending the clinical settings. Cognitive impairment and neuroendocrine dysregulation had been reported in patients with depression and patients with $\mathrm{CTTH}$.

Objective: To assess the cognitive performance and investigate its possible relations to neuroendocrine levels in patients with $\mathrm{CTTH}$.

Subjects and methods: Patients with $\mathrm{CTTH}$, depression, and control subjects were recruited. СTTH was diagnosed according to the International Classification of Headache Disorders. Cognitive performance, depression severity, and pain intensity were assessed by the Montreal Cognitive Assessment Arabic version, Beck's Depression Inventory, and McGill Pain Questionnaire respectively. Blood samples were collected in the morning within 60 min after waking up from 8:00 to 9:00 a.m. to measure serum levels of basal plasma CRH, ACTH, Cortisol, TSH, FT3, and FT4.
\end{abstract}

Results: Both patients with $\mathrm{CTTH}$ and depression had impaired cognitive performance. Patients with $\mathrm{CTTH}$ and patients with depression had altered the hypothalamus-pituitary-adrenal axis, and pituitary-thyroid axis. The hormonal levels significantly correlated with cognitive function in patient groups, especially patients with $\mathrm{CTTH}$.

Conclusion: Patients with $\mathrm{CTTH}$ had cognitive dysfunction which could be related to neuroendocrine hormonal dysregulation.

Keywords: Chronic tension-type headache, Depression, Cognitive impairment, Neuroendocrine hormones

\section{Introduction}

Tension-type headache (TTH) is the most common head pain seen in clinical practice. Headache is the third most prevalent pain worldwide [1]. TTH is defined as a mild to moderate band-like pressure headache associated with some somatic and emotional symptoms. The frequency and duration of TTH varied from infrequent episodes of a headache to frequent, long-lasting, or even chronic. Chronic tension-

\footnotetext{
* Correspondence: mamdouhali19702001@gmail.com

${ }^{1}$ Neurology Department, College of Medicine, Prince Sattam bin Abdulaziz University, Alkharj, Kingdom of Saudi Arabia

${ }^{2}$ Neurology Department, Faculty of Medicine, Minia University, Minia, Egypt Full list of author information is available at the end of the article
}

type headache (CTTH) occurs over 15 days per month at least for 3 months per year, and lasts hours to days, or unremitting [2]. In a population-based study in Denmark, the authors reported that about a third of the studied population had episodic TTH, and 2 to $3 \%$ of the studied population had CTTH [3]. The lifetime prevalence was $79 \%$ and $3 \%$ for TTH and CTTH respectively in another study [4]. In the Kingdom of Saudi Arabia, 8 to $12 \%$ of the Saudi population suffers from TTH $[5,6]$. Patients with CTTH often suffer from memory impairment, sleep disturbance, and other psychiatric disorders especially anxiety and depression [7]. Although it is common, TTH has low healthcare and public profile than 
migraine. Several studies reported impaired cognitive performance in patients with migraine $[8,9]$. However, studies that evaluate the cognitive function of patients with CTTH are rare, the previous study reported cognitive impairment and neuroendocrine dysregulation in those patients [10]. Moreover, epidemiological studies revealed that depression is highly prevalent in CTTH patients [11-14]. Patients with depression tend to have neuroendocrine dysregulation, which includes a hyperactive hypothalamic-pituitary-adrenal axis (HPA) and non-suppression of cortisol by dexamethasone [15]. Furthermore, many neuroendocrine hormones dysregulation, including hormones of the hypothalamus-pituitary-adrenal (HPA) axis, hypothalamus-pituitary-thyroid (HPT) axis, and hypothalamus-pituitary-gonadal (HPG) axis were associated and correlated with impaired cognitive performance in different medical disorders [16-26]. In addition, growing evidence indicated that corticotropin releasing hormone $(\mathrm{CRH})$ involved in learning and memory. Emerging evidence suggested that thyroid hormones involved in cognitive performance $[17,23,27]$.

The cognitive impairment reported in CTTH could be the result of neuroendocrine hormones alteration or the effect of associated depression.

In this study, we aimed to (1) assess the cognitive performance and measure the serum concentration of neuroendocrine hormones [corticotropin-releasing hormone $(\mathrm{CRH})$, adrenocorticotropic hormone (ACTH), cortisol, thyroid-stimulating hormone (TSH), free triiodothyronine (FT3), and free thyroxine (FT4)] in patients with CTTH. (2) Investigate the possible relations between cognitive performance and neuroendocrine hormones.

\section{Subjects and methods}

In a cross-sectional case-control study, we investigated 100 patients with CTTH, 97 patients with depression, and 105 control subjects without headache or depression for cognitive performance and serum levels of neuroendocrine hormones. Patients were recruited from neurology and psychiatry outpatient clinics of Prince Sattam bin Abdulaziz University Hospital in Alkharj City, Kingdom of Saudi Arabia, from February 2017 to January 2019. Control subjects were selected from the physiotherapy unit of the same hospital. Subjects with infectious diseases, disease of the endocrine system, disease of the immune system, or psychiatric disorder other than mild or moderate depression were excluded. CTTH was diagnosed according to the International Classification of Headache Disorders (ICHD)-III beta criteria [2], but a strict version was used instead-all patients must have all of the following four headache characteristics: bilateral, mild-to-moderate intensity, non-pulsating headache not aggravated by routine physical activity, and their headaches must not be associated with any of nausea, vomiting, photophobia, or phonophobia [28].

Depression was diagnosed in accordance with the Diagnostic and Statistical Manual of Mental Disorders fifth edition [29]. Cognitive performance, depression severity, and pain intensity were assessed by the Montreal Cognitive Assessment Arabic version (MoCA) [30], Beck's Depression Inventory-II (BDI) [31], and McGill Pain Questionnaire (MPQ) short form [32], respectively.

Blood samples were collected under aseptic precaution using sterile disposable syringes in the morning within $60 \mathrm{~min}$ after waking up from 8:00 to 9:00 am. Patients with CTTH were in active episodes of headache when the blood samples were obtained. Blood samples were immediately centrifuged at $3000 \mathrm{rpm}$ for $5 \mathrm{~min}$ and sera were separated and kept in labeled sterile microtubes at $-80{ }^{\circ} \mathrm{C}$ until the hormones were assayed. An enzyme-linked immunosorbent assay was performed to detect the basal serum concentrations of neuroendocrine hormones including $\mathrm{CRH}, \mathrm{ACTH}$, CORTISOL, TSH, FT3, and FT4. This assay was processed according to the instructions and regulations of the used kits.

For all the participants, written informed consent was obtained after the study procedures had been explained. The study protocol and the consent form were reviewed and accepted by the Institutional Review Board of College of Medicine, Prince Sattam bin Abdul-Aziz University.

\section{Statistical analysis}

The data were analyzed using the Statistical Package for the Social Sciences (SPSS) 13.0. Descriptive statistics were calculated. The statistical analysis was performed with non-parametric chi-square between gender, and pain severity in the studied groups. Analysis of variance (ANOVA) was used to test the differences in demographic, clinical, and hormonal levels among subgroups. Pearson's correlation coefficient $(r)$ was used to analyze the association between the different variables. Regression analysis was performed to identify the effect of different hormones on cognitive function. Values of $p<0.05$ were considered to be statistically significant.

\section{Results}

One hundred (40 male and 60 female) patients with CTTH, 97 (34 male and 63 female) patients with depression, and 105 (42 male and 63 female) age, sex, and years of education matched control volunteers were enrolled in this study. Patients with depression had significantly higher BDI scores compared to patients with CTTH and 
Table 1 Demographic characteristics of the subjects

\begin{tabular}{|c|c|c|c|c|c|c|c|}
\hline \multicolumn{2}{|l|}{ Variables } & $\begin{array}{l}\text { CTTH } \\
\text { N } 100 \\
\text { I }\end{array}$ & $\begin{array}{l}\text { Depression } \\
\text { N } 97 \\
\text { ॥ }\end{array}$ & $\begin{array}{l}\text { Control } \\
\text { N } 105 \\
\text { III }\end{array}$ & $p$ & & \\
\hline \multicolumn{8}{|c|}{ Age in years } \\
\hline \multicolumn{2}{|c|}{ mean $\pm S D$} & $35.31 \pm 6.95$ & $36.24 \pm 7.20$ & $35.51 \pm 7.35$ & NS & & \\
\hline \multirow[t]{2}{*}{ Male } & no. & 40 & 34 & 42 & NS & & \\
\hline & $\%$ & $40 \%$ & $35.10 \%$ & $40 \%$ & & & \\
\hline \multirow[t]{2}{*}{ Female } & no. & 60 & 63 & 63 & & & \\
\hline & $\%$ & $60 \%$ & $64.90 \%$ & $60 \%$ & & & \\
\hline \multicolumn{5}{|c|}{ Years of education in years } & NS & & \\
\hline \multicolumn{2}{|c|}{ mean $\pm S D$} & $8.48 \pm 3.04$ & $8.09 \pm 2.89$ & $8.66 \pm 3.19$ & & & \\
\hline \multicolumn{2}{|l|}{ BDI score } & & & & | vs || & | vs ||| & II vs III \\
\hline \multicolumn{2}{|c|}{ mean $\pm S D$} & $23.04 \pm 7.37$ & $25.73 \pm 5.19$ & $4.74 \pm 1.69$ & $p<0.001$ & & \\
\hline \multicolumn{2}{|c|}{ MoCA score } & & & & | vs ||| & II vs III & \\
\hline \multicolumn{2}{|c|}{ mean $\pm S D$} & $21.92 \pm 4.13$ & $21.72 \pm 4.30$ & $27.12 \pm 1.33$ & $p<0.001$ & $p<0.001$ & \\
\hline
\end{tabular}

$\overline{C T T H}=$ chronic tension-type headache, $B D I=$ Beck's Depression Inventory, MoCA = Montreal Cognitive Assessment. Significance level was set at $p<0.05$

control $(p<0.01)$. Control volunteers had significantly higher scores of cognitive performances $(p<$ 0.001) while no significant difference between patients with CTTH and patients with depression (Table 1). Seventeen (17\%) patients with CTTH and 3 (3.10\%) patients with depression experienced excruciating pain. The difference in pain severity between them was significant $(p<0.01)$ (Table 2$)$. The measured hormonal levels in the studied population fall within the normal reference range. For the HPA axis, the serum levels of $\mathrm{CRH}, \mathrm{ACTH}$, and cortisol were significantly higher in patients with $\mathrm{CTTH}$ and patients with depression than control $(p<0.001)$, patients with depression had significantly higher $\mathrm{CRH}$ and ACTH than patients with CTTH $(p<01001)$. For pituitary-thyroid (PT) axis, patients with CTTH and patients with depression had significantly higher serum levels of TSH $(p<0.01)$ but significantly lower FT3 and FT4 levels compared to control group, while,

Table 2 Pain severity in patients with $\mathrm{CTTH}$ and patients with depression

\begin{tabular}{|c|c|c|c|c|c|c|}
\hline \multirow[t]{3}{*}{ Variables } & \multirow{2}{*}{\multicolumn{2}{|c|}{$\frac{\mathrm{CTTH}}{\mathrm{N} 100}$}} & \multicolumn{2}{|c|}{ Depression } & \multicolumn{2}{|c|}{ Significance } \\
\hline & & & \multirow{2}{*}{$\begin{array}{l}\bar{N} \\
N\end{array}$} & \multirow{2}{*}{$\begin{array}{l}97 \\
\%\end{array}$} & \multirow[t]{2}{*}{$\overline{x^{2}}$} & \multirow[t]{2}{*}{$p$} \\
\hline & $\bar{N}$ & $\%$ & & & & \\
\hline Mild & 4 & $4 \%$ & 0 & $0.00 \%$ & NS & \\
\hline Discomforting & 21 & $21 \%$ & 25 & $25.80 \%$ & NS & \\
\hline Distressing & 34 & $34 \%$ & 45 & $46.4 \%$ & NS & \\
\hline Horrible & 24 & $24 \%$ & 24 & $24.70 \%$ & NS & \\
\hline Excruciating & 17 & $17 \%$ & 3 & $3.10 \%$ & 9.80 & 0.002 \\
\hline
\end{tabular}

$\overline{\mathrm{CTTH}}=$ chronic tension-type headache, level was set at $p<0.05$
FT3 and FT4 were significantly lower $(p<0.01)$ in patients with depression than patients with CTTH (Table 3).

Correlations between serum hormonal levels and cognitive performance and depression severity in patients with CTTH and patients with depression were presented in Tables 4 and 5. In patients with CTTH, the serum levels of $\mathrm{CRH}, \mathrm{ACTH}$, cortisol, and TSH had significant negative effects on MoCA scores $(r-.314, p=.001 ; r$ $-.378, p=.000 ; r-.222, p .027 ; r-.388, p=.000$, respectively) while the serum level of FT4 had positive effect on the MoCA score $(r .372, p=.000)$. The linear regression analysis revealed that ACTH and TSH were the independent hormones that were related to cognitive function (Tables 6 and 7). TSH was negatively correlated significantly with MoCA in patients with depression $(r$ $-.221, p=.029)$.

The serum levels of $\mathrm{CRH}, \mathrm{ACTH}, \mathrm{TSH}$ were positively $(r .202, p=.044 ; r .285, p=.004 ; r .416, p=.000$, respectively) and serum level of FT4 was negatively $(r$ $-.388, p=.000)$ correlated with BDI score among patients with CTTH. In patients with depression, the serum levels of CRH, ACTH, cortisol, and TSH were positive $(r .403, p=.000 ; r .288, p=.004 ; r$ 0427, $p=$ $.000 ; r .834, p=.000$, respectively) and serum levels of FT3 and FT4 were negative $(r-.357, p=.000$ and $r$ $-.523, p=.000)$ correlated with BDI score.

\section{Discussion}

Patients with chronic daily headache showed reduced quality of life [33, 34], the chronic headache reduces the workdays times, lost days with household activities, affects family, and social relationships [35, 36]. Patients 
Table 3 Serum levels of hormones in studied subjects

\begin{tabular}{|c|c|c|c|c|c|c|}
\hline Variables & $\begin{array}{l}\text { CTTH I } \\
N 100 \\
\text { mean } \pm \text { SD }\end{array}$ & $\begin{array}{l}\text { Depression II } \\
N 97 \\
\text { mean } \pm \text { SD }\end{array}$ & $\begin{array}{l}\text { Control III } \\
\text { N } 105 \\
\text { mean } \pm \text { SD }\end{array}$ & $p$ & & \\
\hline $\mathrm{CRH}(\mathrm{pmol} / \mathrm{l})$ & $1.81 \pm 0.68$ & $2.31 \pm 0.58$ & $1.03 \pm 0.25$ & $\begin{array}{l}\text { | vs || } \\
p<0.001\end{array}$ & $\begin{array}{l}\text { | vs ||| } \\
p<0.001\end{array}$ & $\begin{array}{l}\| \text { vs III } \\
p<0.001\end{array}$ \\
\hline $\mathrm{ACTH}(\mathrm{pmol} / \mathrm{l})$ & $4.26 \pm 3.02$ & $5.93 \pm 3.23$ & $3.18 \pm 1.62$ & $\begin{array}{l}\text { | vs || } \\
p<0.001\end{array}$ & $\begin{array}{l}\text { | vs ||| } \\
p<0.01\end{array}$ & $\begin{array}{l}\| \text { vs III } \\
p<0.001\end{array}$ \\
\hline TSH $(\mu \mathrm{lU} / \mathrm{ml})$ & $2.18 \pm 0.38$ & $2.28 \pm 0.34$ & $1.92 \pm 0.33$ & $\begin{array}{l}\text { I vs III } \\
p<0.001\end{array}$ & $\begin{array}{l}\| \text { vs III } \\
p<0.001\end{array}$ & \\
\hline Cortisol (nmol/l) & $462.98 \pm 167.22$ & $445.56 \pm 199.95$ & $243.56 \pm 106.95$ & $\begin{array}{l}\text { I vs III } \\
p<0.001\end{array}$ & $\begin{array}{l}\| \text { vs III } \\
p<0.001\end{array}$ & \\
\hline FT3 (pmol/l) & $5.15 \pm 0.37$ & $4.89 \pm 0.52$ & $5.45 \pm 0.42$ & $\begin{array}{l}\text { | vs || } \\
p<0.001\end{array}$ & $\begin{array}{l}\text { I vs III } \\
p<0.001\end{array}$ & $\begin{array}{l}\| \text { vs III } \\
p<0.001\end{array}$ \\
\hline FT4 (pmol/l) & $14.43 \pm 0.88$ & $14.09 \pm 0.84$ & $14.89 \pm 1.07$ & $\begin{array}{l}\text { I vs || } \\
p<0.01\end{array}$ & $\begin{array}{l}\text { I vs III } \\
p<0.01\end{array}$ & $\begin{array}{l}\| \text { vs III } \\
p<0.001\end{array}$ \\
\hline
\end{tabular}

$C T T H=$ chronic tension-type headache, $C R H=$ corticotropin-releasing hormone, $A C T H=$ adrenocorticotropic hormone, $T S H=$ thyroid-stimulating hormone, $F T 3=$ free triiodothyronine, FT4 $=$ free thyroxine, significance level was set at $p<0.05$

with CTTH usually suffering from poor cognitive performance. In this study, both patients with CTTH and patients with depression had cognitive impairment without significant differences between them. A study done by Moore et al. [37] suggested that patients who experiencing TTH had impaired attention. Another study [38] revealed that children with CTTH were more likely to have weaker verbal skills. Similarly, adult patients with CTTH with a history of childhood TTH had poor verbal and performance intelligence quotient (IQ) scores and reading difficulties [39]. Most recently, Ping et al. [10] reported an impairment in cognitive function, especially memory, in patients with CTTH. Hammar et al. [40] found that depressed patients showed impaired cognitive performance on cognitively demanding tasks when symptomatic and that the impairment prevails after 6 months, despite significant improvement in the depression symptoms.

In this study, most patients (63\%) with CTTH had depression. This finding is supported by the study of Lampl et al. [41] who suggested that subjects with TTH exhibit comorbid depression, and almost half of the patients with CTTH were diagnosed as having mild or moderate depression [11-13].

In the present study, the hypothalamus-pituitaryadrenal (HPA) axis was altered (higher CRH, ACTH, and cortisol) in patient groups compared to control volunteers. At the same time, the patient groups had dysregulated pituitary-thyroid (PT) axis (higher TSH, and lower FT3, and FT4) than control volunteers. Patients with depression had more prominent HPA and PT dysfunction than patients with CTTH. The exact mechanism of altered pituitary-thyroid function in non-thyroidal illness associated with neuropsychiatric illness remains unclear [42], it might be due to neurotransmitters alteration [43] or change in TSH secretion with centrally mediated TSH dysregulation [44]. A recent study reported similar findings in patients with CTTH with hyperactive HPA axis and hypoactive HPT axis [10]. Alteration in HPA axis activity was reported to be common in dementia and progressive cognitive impairment [45-48]. Some previous studies reported similar HPA and HPT dysfunction in patients with depression [49-52], and the dysregulation of HPA axis activity was considered to be the hallmarks of major depression [53, 54]. The correlation between serum levels of neuroendocrine hormones and cognitive functions showed significant negative effects of $\mathrm{CRH}, \mathrm{ACTH}$, cortisol, and TSH and positive effects of FT4 on cognitive function in patients with CTTH, and ACTH, and TSH appeared to be the independent hormones related to cognitive

Table 4 Correlations between serum hormonal levels and BDI score, and MoCA score in patients with CTTH

\begin{tabular}{llllllll}
\hline & & CRH & ACTH & TSH & Cortisol & Free T3 & Free T4 \\
\hline BDI & Pearson correlation & $.202^{*}$ & $.285^{* *}$ & $.416^{* *}$ & .099 & .015 & $-.388^{* *}$ \\
& Sig. & $p<0.05$ & $p<0.01$ & $p<0.001$ & .329 & .880 & $p<0.001$ \\
MoCA & Pearson correlation & $-.314^{* *}$ & $-.378^{* *}$ & $-.388^{* *}$ & $-.222^{*}$ & .089 & $.372^{* *}$ \\
& Sig. & $p<.01$ & $p<0.001$ & $p<0.001$ & $p<.05$ & .376 & $p<0.001$ \\
\hline
\end{tabular}

$B D I=$ Beck's Depression Inventory, $M O C A=$ Montreal Cognitive Assessment, $C R H=$ corticotropin-releasing hormone, $A C T H=$ adrenocorticotropic hormone, $T S H=$ thyroid-stimulating hormone, $F T 3=$ free triiodothyronine, $F T 4=$ free thyroxine, significance level was set at $p<0.05$

* Correlation is significant at the 0.05 level ** Correlation is significant at the 0.01 level 
Table 5 Correlations between serum hormonal levels and BDI score, and MoCA score in patients with depression

\begin{tabular}{llllllll}
\hline & & CRH & ACTH & TSH & Cortisol & Free T3 & Free T4 \\
\hline BDI & Pearson correlation & $.403^{* *}$ & $.288^{* *}$ & $.834^{* *}$ & $.427^{* *}$ & $-.357^{* *}$ & $-.523^{* *}$ \\
& Sig. & $p<0.001$ & $p<0.01$ & $p<0.001$ & $p<0.001$ & $p<0.001$ & $p<0.001$ \\
MoCA & Pearson correlation & -.006 & .065 & $-.221^{*}$ & -.076 & -.002 & .116 \\
& Sig. & .955 & .529 & $\mathrm{P}<0.05$ & .462 & .984 & .260 \\
\hline
\end{tabular}

$B D I=$ Beck's Depression Inventory, MoCA = Montreal Cognitive Assessment, $C R H=$ corticotropin-releasing hormone, $A C T H=$ adrenocorticotropic hormone, $T S H=$ thyroid-stimulating hormone, FT3 = free triiodothyronine, FT4 = free thyroxine, significance level was set at $p<0.05$

* Correlation is significant at the 0.05 level ${ }^{* *}$ Correlation is significant at the 0.01 level

function. However, in patients with depression, the only significant negative correlation was reported with TSH which might suggest that the cognitive impairment in patients with CTTH may be related to alterations in functions of HPA and PT axes and not due to the presence of comorbid depression, specially, patients with depression had more prominent hormonal dysregulation than patients with CTTH.

Endocrine hormones play an essential role in maintaining brain function, including cognitive performance [55]. A temporary increase in $\mathrm{CRH}$ facilitates learning and memory that are hippocampal-dependent [17]; however, prolonged elevation could impair spatial memory performance [18]. Decreased response of ACTH to CRH had also been related to cognitive dysfunction [20]. Previous study had proposed that cortisol can affect the prefrontal cortex and altered higher cognitive functions [56]. A negative association was reported in previous studies between endogenous cortisol levels and cognitive measures of processing speed, and executive function [57, 58]. The relation between HPA function and memory is mixed, while cortisol appears to enhance memory consolidation, it more often impairs memory retrieval $[59,60]$.

HPT hormones are associated with cognitive function. The thyrotropin-releasing hormone has direct or indirect effects on cognitive abilities and mood [55]. Thyroid dysfunction are associated with decreased executive abilities [61]. Adults with lower levels of thyroid hormones had poor cognitive and psychomotor function than those with a higher level of thyroid hormones [23]. Furthermore, low FT3 and high TSH had been related to cognitive deterioration [62]. In addition, subjects with high TSH levels might be more exposed to working memory and visuospatial and/or visuo-constructional deterioration [63, 64].

Many studies have shown that hormones in HPA and HPT axes can directly or indirectly affect the prefrontal cortex and hippocampus, thereby affecting cognitive performance $[23-27,52,56,65]$. In the hippocampus, $\mathrm{CRH}$ is expressed in inhibitory interneurons and primarily interacts with $\mathrm{CRH}$ receptor 1 [19]. At the same time, thyroid hormone and adrenal steroids have a major biological role in the differentiation and survival of neurons [66]. Cortisol passes across the blood-brain barrier probably through binding to thyroid hormones [66]. Cortisol receptors are well-represented in many important cognitive related areas of the brain including the limbic structures, prefrontal cortex, and anterior cingulate cortex $[16,67]$. As a result, the HPA and HPT dysfunction can affect cognitive function probably as a result of disturbances of those brain structures [68-72].

The present study had some limitations including the lack of measurement of Thyrotropin-releasing hormone (TRH) that evaluates the hypothalamus-pituitary-thyroid axis accurately; however, it was not available in our center. Also, we did not analyze the different domains of cognitive function as we thought it is beyond the scope of our aim.

Based on our results, we recommend periodic neuroendocrine hormones assessment for early prediction of

Table 6 The regression analysis for MoCA in patients with CTTH

\begin{tabular}{llllll}
\hline Model & \multicolumn{2}{l}{$\begin{array}{l}\text { Standardized coefficients } \\
\text { Beta }\end{array}$} & $\mathrm{t}$ & Sig. & \multicolumn{2}{l}{ 95\% confidence interval for B } \\
\cline { 5 - 6 } & .048 & & .815 & -2.151 & Upper bound \\
\hline CRH & -.323 & .234 & $p<0.05$ & -.791 & -.092 \\
ACTH & -.340 & -2.510 & $p<0.05$ & -7.342 & -.019 \\
TSH & .154 & -1.996 & .290 & -.003 & .011 \\
Cortisol & .028 & 1.064 & .793 & -1.978 & 2.582 \\
Free T3 & .025 & .263 & .919 & -2.117 & 2.346 \\
Free T4 & .102 & & & \\
\hline
\end{tabular}

$C R H=$ corticotropin-releasing hormone, $A C T H=$ adrenocorticotropic hormone, $T S H=$ thyroid-stimulating hormone, $F T 3=$ free triiodothyronine, $F T 4=$ free thyroxine, significance level was set at $p<0.05$ 
Table 7 The regression analysis for MoCA in patients with depression

\begin{tabular}{llllll}
\hline Model & \multicolumn{2}{l}{$\begin{array}{l}\text { Standardized coefficients } \\
\text { Beta }\end{array}$} & $\mathrm{t}$ & Sig. & \multicolumn{2}{l}{ 95\% Confidence Interval for B } \\
\cline { 5 - 6 } & .295 & 1.485 & .141 & Lower bound & Upper bound \\
\hline CRH & .191 & 1.740 & .085 & -.729 & .047 \\
ACTH & -.335 & -2.176 & $p<0.05$ & -.036 & -.362 \\
TSH & -.047 & -.428 & .670 & -.006 & .004 \\
Cortisol & -.083 & -.591 & .556 & -2.950 & 1.596 \\
Free T3 & .222 & .971 & .334 & -1.180 & 3.436 \\
Free T4 & CRH & & & & \\
\hline
\end{tabular}

$C R H=$ corticotropin-releasing hormone, $A C T H=$ adrenocorticotropic hormone, $T S H=$ thyroid-stimulating hormone, $F T 3=$ free triiodothyronine, $F T 4=$ free thyroxine, significance level was set at $p<0.05$

changes that may emerge from hormonal dysregulation in patients with CTTH.

\section{Conclusion}

Patients with CTTH had cognitive dysfunction and prominent hormonal changes. The hormonal changes may be the cause of the cognitive decline in patients with CTTH.

\section{Acknowledgements}

Not applicable

\section{Authors' contributions}

All authors contributed to the research idea. MAK, AMK, and DAM contributed to the data collection. MAK, AMK, and ASA analyzed and interpreted the data. MAK, AMK, and YMA completed the first draft of the article. All authors were involved in drafting the article or revising it critically for important intellectual content, and all authors read and approved the final version to be published.

\section{Funding}

There is no source of funding for this research.

\section{Availability of data and materials}

All datasets generated and analyzed during the current study are not publicly available but are available by reasonable request from the corresponding author.

\section{Ethics approval and consent to participate}

The study was approved by the Institutional Review Board of College of Medicine, Prince Sattam Bin Abdulaziz University, KSA, on 7 November 2016. Written consent was taken from all of the participants after explaining the details, benefits, and risks to them.

\section{Consent for publication}

Not applicable.

\section{Competing interests}

The authors declare that they have no competing interests.

\section{Author details}

${ }^{1}$ Neurology Department, College of Medicine, Prince Sattam bin Abdulaziz University, Alkharj, Kingdom of Saudi Arabia. ${ }^{2}$ Neurology Department, Faculty of Medicine, Minia University, Minia, Egypt. ${ }^{3}$ Psychiatry Department, College of Medicine, Prince Sattam bin Abdulaziz University, Alkharj, Kingdom of Saudi Arabia. ${ }^{4}$ Psychiatry Department, Faculty of Medicine, Minia University, Minia, Egypt. ${ }^{5}$ Department of Internal Medicine, Faculty of Medicine, Minia University, Minia, Egypt. ${ }^{6}$ Faculty of Medicine, Minia University, Minia, Egypt.
Received: 17 June 2019 Accepted: 7 January 2020

Published online: 29 January 2020

\section{References}

1. Vos T, Abajobir A, Abate K, Abbafati C, Abbas K, Abd-Allah F. GBD 2016 Disease and Injury Incidence and Prevalence Collaborators. Global, regional, and national incidence, prevalence, and years lived with disability for 328 diseases and injuries for 195 countries, 1990-2016: a systematic analysis for the Global Burden of Disease Study 2016. Lancet. 2017:390(10100):1211-59.

2. Headache Classification Committee of the International Headache S. The International Classification of Headache Disorders, 3rd edition (beta version). Cephalalgia. 2013;33(9):629-808.

3. Lyngberg A, Rasmussen B, Jørgensen $T$, Jensen R. Incidence of primary headache: a Danish epidemiologic follow-up study. Am J Epidemiol. 2005; 161(11):1066-73.

4. Rasmussen BK, Jensen R, Schroll M, Olesen J. Epidemiology of headache in a general population-a prevalence study. J Clin Epidemiol. 1991;44(11): 1147-57.

5. Jabbar MA, Ogunniyi A. Sociodemographic factors and primary headache syndromes in a Saudi community. Neuroepidemiology. 1997;16(1):48-52.

6. Rajeh SA, Awada A, Bademosi O, Ogunniyi A. The prevalence of migraine and tension headache in Saudi Arabia: a community-based study. Eur J Neurol. 1997:4(5):502-6.

7. Bag B, Hacihasanoglu R, Tufekci F. Examination of anxiety, hostility and psychiatric disorders in patients with migraine and tension-type headache. Int J Clin Pract. 2005;59(5):515-21.

8. Öze A, Nagy A, Benedek G, Bodosi B, Kéri S, Pálinkás É, et al. Acquired equivalence and related memory processes in migraine without aura. Cephalalgia. 2017:37(6):532-40.

9. Gil-Gouveia R, Oliveira AG, Martins IP. Cognitive dysfunction during migraine attacks: a study on migraine without aura. Cephalalgia. 2015;35(8):662-74.

10. Qu P, Yu JX, Xia L, Chen GH. Cognitive Performance and the Alteration of Neuroendocrine Hormones in Chronic Tension-Type Headache. Pain Pract. 2018:18(1):8-17.

11. Goncalves J, Monteiro P. Psychiatric analysis of patients with tension-type headache. Tensiontype headache: Classification, mechanisms, and treatment; 1993. p. 167-72.

12. Guidetti V, Galli F, Fabrizi PA, Giannantoni A, Napoli L, Bruni O, et al. Headache and psychiatric comorbidity: clinical aspects and outcome in an 8-year follow-up study. Cephalalgia. 1998;18(7):455-62.

13. Holroyd KA, Stensland M, Lipchik GL, Hill KR, O'Donnell FS, Cordingley G. Psychosocial correlates and impact of chronic tension-type headaches. Headache. 2000;40(1):3-16.

14. Puca F, Genco S, Prudenzano M, Savarese M, Bussone G, D'Amico D, et al. Psychiatric comorbidity and psychosocial stress in patients with tension-type headache from headache centers in Italy. Cephalalgia. 1999:19(3):159-64

15. Barden N, Reul J, Holsboer F. Do antidepressants stabilize mood through actions on the hypothalamic-pituitary-adrenocortical system? Trends Neurosci. 1995;18(1):6-11.

16. Joëls M, Baram TZ. The neuro-symphony of stress. Nat Rev Neurosci. 2009; 10(6):459

17. Row BW, Dohanich GP. Post-training administration of corticotropinreleasing hormone $(\mathrm{CRH})$ enhances retention of a spatial memory through 
a noradrenergic mechanism in male rats. Neurobiol Learn Mem. 2008;89(4): 370-8.

18. Heinrichs S, Stenzel-Poore M, Gold L, Battenberg E, Bloom F, Koob G, et al. Learning impairment in transgenic mice with central overexpression of corticotropin-releasing factor. Neuroscience. 1996;74(2):303-11.

19. Chen Y, Brunson K, Adelmann G, Bender R, Frotscher M, Baram T. Hippocampal corticotropin releasing hormone: pre-and postsynaptic location and release by stress. Neuroscience. 2004;126(3):533-40.

20. Sandström A, Peterson J, Sandström E, Lundberg M, NYSTROM ILR, Nyberg $L$, et al. Cognitive deficits in relation to personality type and hypothalamicpituitary-adrenal (HPA) axis dysfunction in women with stress-related exhaustion. Scand J Psychol. 2011;52(1):71-82.

21. Ackermann S, Hartmann F, Papassotiropoulos A, de Quervain DJ-F, Rasch B. Associations between basal cortisol levels and memory retrieval in healthy young individuals. J Cogn Neurosci. 2013;25(11):1896-907.

22. Chen G, Xia L, Wang F, Li XW, Jiao CA. Patients with chronic insomnia have selective impairments in memory that are modulated by cortisol. Psychophysiology. 2016;53(10):1567-76.

23. Beydoun M, Beydoun H, Kitner-Triolo M, Kaufman J, Evans M, Zonderman A. Thyroid hormones are associated with cognitive function: moderation by sex, race, and depressive symptoms. J Clin Endocrinol Metab. 2013;98(8): 3470-81.

24. Bagger YZ, Tankó LB, Alexandersen P, Qin G, Christiansen C, Group PS. Early postmenopausal hormone therapy may prevent cognitive impairment later in life. Menopause. 2005;12(1):12-7.

25. MacLennan AH, Henderson WW, Paine BJ, Mathias J, Ramsay EN, Ryan P, et al. Hormone therapy, timing of initiation, and cognition in women aged older than 60 years: the REMEMBER pilot study. Menopause. 2006;13(1):28-36.

26. Ghazvini H, Khaksari M, Esmaeilpour K, Shabani M, Asadi-Shekaari M, Khodamoradi $M$, et al. Effects of treatment with estrogen and progesterone on the methamphetamine-induced cognitive impairment in ovariectomized rats. Neurosci Lett. 2016;619:60-7.

27. Berent-Spillson A, Briceno E, Pinsky A, Simmen A, Persad CC, Zubieta J-K, et al. Distinct cognitive effects of estrogen and progesterone in menopausal women. Psychoneuroendocrinology. 2015;59:25-36.

28. Chen WT, Chou KH, Lee PL, Hsiao FJ, Niddam DM, Lai KL, et al. Comparison of gray matter volume between migraine and "strict-criteria" tension-type headache. J Headache Pain. 2018;19(1):4.

29. Edition F. Diagnostic and statistical manual of mental disorders. Am Psychiatric Assoc. 2013.

30. Rahman TTA, El Gaafary MM. Montreal Cognitive Assessment Arabic version: reliability and validity prevalence of mild cognitive impairment among elderly attending geriatric clubs in Cairo. Geriatr Gerontol Int. 2009;9(1):54-61.

31. Beck AT, Steer RA, Brown GK. Beck depression inventory-II. San Antonio. 1996;78(2):490-8.

32. Melzack R. The short-form McGill Pain Questionnaire. Pain. 1987;30(2):191-7.

33. Stovner LJ, Andrée C. Impact of headache in Europe: a review for the Eurolight project. J Headache Pain. 2008;9(3):139.

34. Adams AM, Serrano D, Buse DC, Reed ML, Marske V, Fanning KM, et al. The impact of chronic migraine: The Chronic Migraine Epidemiology and Outcomes (CaMEO) Study methods and baseline results. Cephalalgia. 2015; 35(7):563-78.

35. Steiner TJ, Stovner LJ, Katsarava Z, Lainez JM, Lampl C, Lantéri-Minet M, et al. The impact of headache in Europe: principal results of the Eurolight project. J Headache Pain. 2014;15(1):31.

36. Zebenholzer K, Andree C, Lechner A, Broessner G, Lampl C, Luthringshausen $G$, et al. Prevalence, management and burden of episodic and chronic headaches-a cross-sectional multicentre study in eight Austrian headache centres. J Headache Pain. 2015;16(1):46.

37. Moore DJ, Keogh E, Eccleston C. Headache impairs attentional performance. PAIN ${ }^{\oplus}$. 2013;154(9):1840-5.

38. Smith AP. Acute tension-type headaches are associated with impaired cognitive function and more negative mood. Front Neurol. 2016;7:42.

39. Waldie KE, Welch D. Cognitive function in tension-type headache. Curr Pain Headache Rep. 2007;11(6):454-60

40. Hammar $\AA$, Lund A, Hugdahl K. Long-lasting cognitive impairment in unipolar major depression: a 6-month follow-up study. Psychiatry Res. 2003; 118(2):189-96.

41. Lampl C, Thomas H, Tassorelli C, Katsarava Z, Laínez JM, Lantéri-Minet M, et al. Headache, depression and anxiety: associations in the Eurolight project. J Headache Pain. 2016;17(1):59.
42. Nader S, Warner MD, Doyle S, Peabody CA. Euthyroid sick syndrome in psychiatric inpatients. Biol Psychiatry. 1996;40(12):1288-93.

43. Lambert T, Davidson R, Mc Lellan G. Euthyroid hyperthyroxinaemia in acute psychiatric admissions. London: Sage Publications Sage; 1987.

44. Roca R, Blackman MR, Ackerley M, Harman S, Gregerman R. Thyroid hormone elevations during acute psychiatric illness: relationship to severity and distinction from hyperthyroidism. Endocrine Res. 1990;16(4):415-47.

45. Csernansky JG, Dong H, Fagan AM, Wang L, Xiong C, Holtzman DM, et al. Plasma cortisol and progression of dementia in subjects with Alzheimertype dementia. Am J Psychiatry. 2006;163(12):2164-9.

46. Lee BK, Glass TA, McAtee MJ, Wand GS, Bandeen-Roche K, Bolla Kl, et al. Associations of salivary cortisol with cognitive function in the Baltimore memory study. Arch Gen Psychiatry. 2007;64(7):810-8.

47. Peavy GM, Salmon DP, Jacobson MW, Hervey A, Gamst AC, Wolfson T, et al. Effects of chronic stress on memory decline in cognitively normal and mildly impaired older adults. Am J Psychiatry. 2009;166(12):1384-91.

48. Schrijvers E, Direk N, Koudstaal PJ, Kirschbaum C, Hofman A, Tiemeier H, et al. Associations of serum cortisol with cognitive function and dementia: the Rotterdam Study. J Alzheimers Dis. 2011;25(4):671-7.

49. Schatzberg AF, Garlow SJ, Nemeroff CB. Molecular and cellular mechanisms in depression. Neuropsychopharmacology The fifth generation of progress; 2002. p. 1039-50.

50. Kessing LV, Willer IS, Knorr U. Volume of the adrenal and pituitary glands in depression. Psychoneuroendocrinology. 2011;36(1):19-27.

51. Wu E-L, Chien I-C, Lin C-H, Chou Y-J, Chou P. Increased risk of hypothyroidism and hyperthyroidism in patients with major depressive disorder: a population-based study. J Psychosom Res. 2013;74(3):233-7.

52. Xia L, Chen G-H, Li Z-H, Jiang S, Shen J. Alterations in hypothalamuspituitary-adrenal/thyroid axes and gonadotropin-releasing hormone in the patients with primary insomnia: a clinical research. PloS One. 2013;8(8): e71065

53. Holsboer F. Stress, hypercortisolism and corticosteroid receptors in depression: implicatons for therapy. J Affect Disord. 2001;62(1-2):77-91.

54. Blazer DG. Depression in late life: review and commentary. J Gerontol A Biol Sci Med Sci. 2003;58(3):M249-M65.

55. Erlanger DM, Kutner KC, Jacobs AR. Hormones and cognition: current concepts and issues in neuropsychology. Neuropsychol Rev. 1999;9(4): 175-207.

56. Arnsten AF. Stress signalling pathways that impair prefrontal cortex structure and function. Nat Rev Neurosci. 2009;10(6):410.

57. Reynolds RM, Strachan MW, Labad J, Lee AJ, Frier BM, Fowkes FG, et al. Morning cortisol levels and cognitive abilities in people with type 2 diabetes: the Edinburgh type 2 diabetes study. Diabet Care. 2010;33(4): 714-20.

58. Venero C, Díaz-Mardomingo C, Pereda-Pérez I, García-Herranz S, Utrera L, Valencia A, et al. Increased morning salivary cortisol levels in older adults with nonamnestic and multidomain mild cognitive impairment. Psychoneuroendocrinology. 2013;38(4):488-98

59. Schwabe L, Joëls M, Roozendaal B, Wolf OT, Oitzl MS. Stress effects on memory: an update and integration. Neurosci Biobehavioral Rev. 2012;36(7): 1740-9.

60. van Ast VA, Cornelisse S, Meeter M, Joëls M, Kindt M. Time-dependent effects of cortisol on the contextualization of emotional memories. Biol Psychiatry. 2013;74(11):809-16.

61. Samuels $\mathrm{MH}$. Cognitive function in untreated hypothyroidism and hyperthyroidism. Curr Opin Endocrinol Diabetes Obes. 2008;15(5):429-33.

62. Chen Z, Liang X, Zhang C, Wang J, Chen G, Zhang H, et al. Correlation of thyroid dysfunction and cognitive impairments induced by subcortical ischemic vascular disease. Brain Behav. 2016;6(4):e00452.

63. Winkler A, Weimar C, Joeckel K-H, Erbel R, Dragano N, Broecker-Preuss M, et al. Thyroid-stimulating hormone and mild cognitive impairment: results of the heinz nixdorf recall study. J Alzheimers Dis. 2016:49(3):797-807.

64. Beydoun MA, Beydoun HA, Rostant OS, Dore GA, Fanelli-Kuczmarski MT, Evans MK, et al. Thyroid hormones are associated with longitudinal cognitive change in an urban adult population. Neurobiol Aging. 2015; 36(11):3056-66

65. Popoli M, Yan Z, McEwen BS, Sanacora G. The stressed synapse: the impact of stress and glucocorticoids on glutamate transmission. Nat Rev Neurosci. 2012;13(1):22

66. Zihl J, Almeida O. Neuropsychology of neuroendocrine dysregulation after traumatic brain injury. J Clin Med. 2015;4(5):1051-62. 
67. Dedovic K, Duchesne A, Andrews J, Engert V, Pruessner JC. The brain and the stress axis: the neural correlates of cortisol regulation in response to stress. Neuroimage. 2009;47(3):864-71.

68. McEwen BS. Sex, stress and the hippocampus: allostasis, allostatic load and the aging process. Neurobiol Aging. 2002;23(5):921-39.

69. Landfield PW, Blalock EM, Chen K-C, Porter NM. A new glucocorticoid hypothesis of brain aging: implications for Alzheimer's disease. Curr Alzheimer Res. 2007;4(2):205-12.

70. de Kloet ER, Sibug RM, Helmerhorst FM, Schmidt M. Stress, genes and the mechanism of programming the brain for later life. Neurosci Biobehav Rev. 2005;29(2):271-81.

71. Sapolsky RM, Romero LM, Munck AU. How do glucocorticoids influence stress responses? Integrating permissive, suppressive, stimulatory, and preparative actions. Endocrine Rev. 2000;21(1):55-89.

72. Lupien SJ, McEwen BS. The acute effects of corticosteroids on cognition: integration of animal and human model studies. Brain Res Rev. 1997;24(1): $1-27$

\section{Publisher's Note}

Springer Nature remains neutral with regard to jurisdictional claims in published maps and institutional affiliations.

\section{Submit your manuscript to a SpringerOpen ${ }^{\odot}$ journal and benefit from:}

- Convenient online submission

- Rigorous peer review

- Open access: articles freely available online

High visibility within the field

- Retaining the copyright to your article

Submit your next manuscript at $\boldsymbol{\nabla}$ springeropen.com 